\title{
Victims and voices: Journalistic sourcing practices and the use of private citizens in online healthcare-system news
}

\begin{abstract}
The opportunity for non-elite actors to share their opinions and experiences is often cited as a key democratic element of the media, developing in recent years alongside a rethinking of the audience as active contributors. Yet, given many of the temporal and resource-related newsroom pressures, the reliance on information subsidies and official or elite voices remains pervasive. This study focuses on coverage of healthcare and health policy, drawing on 14 weeks of news reports $(n=896)$ from five Irish websites. As well as recording the prevalence of private citizens, a novel methodology allows a deeper understanding of how journalists obtained these contributions, such as through "cannibalising" quotes from other media reports. While private citizens have salience in the news, this may primarily be due to journalists' reliance on easily accessible information, rather than more fundamental democratic shifts in news reporting practices. Further analysis shows private citizens rarely appear as detached, informed commentators, but typically as victims with direct negative healthcare experiences. The findings and discussion reinforce the idea of news sourcing as a social system that is continually reproduced, steered by structural forces to do with signification, legitimation and available resources.
\end{abstract}

Keywords: Content analysis; Health journalism; News sources; Ordinary voices; Private citizens;

\begin{abstract}
AUTHOR:
Dawn Wheatley, $\mathrm{PhD}$

School of Communications, Dublin City University, Ireland dawn.wheatley@dcu.ie

This study was part of a research project funded by the Irish Research Council under the Government of Ireland Postgraduate Scholarship Scheme.
\end{abstract}

This is a post-print of an article published in Journalism Studies: https://www.tandfonline.com/doi/full/10.1080/1461670X.2020.1727355 


\section{Victims and voices: Journalistic sourcing practices and the use of private citizens in online healthcare-system news}

\section{INTRODUCTION}

The idea of diverse source contributions offering various representations of "the public" is at the core of many visions of what media should provide. One of Gans' recommendations following his landmark 1970s study was for more perspectives and "bottom-up news", about how ordinary people "are affected by the decisions and acts of high government officials and the rest of the political elite who are journalism's major sources" $(2011$, p. 4). Such coverage, he suggested, would also report on how people view and interpret elite decisions. Yet, despite technological changes altering many aspects of journalism, frustrations remain with elite-based news: decades later, seeking a similar shift towards public-centred perspectives, Blumler and Cushion describe the challenge to "ensure that the situations, experiences and claims of other less powerful and knowledgeable groups are presented sufficiently often in their own terms" (2014, p. 269).

Historically, individuals' trials and tribulations were evident in trends like the US muckraking movement, but the dominance of elite voices became characteristic of most Western, professional approaches. This appears through inherent - often unintentional - biases in news production (Hall et al., 1978; Soloski, 1989) raising questions about the media's use of private individuals, who seemingly lack the legitimacy and credibility of institutional sources (Schneider, 2013). Nevertheless, even within the more detached model, ideals about offering space for the public ensue, such as providing channels, forums, or platforms for extra-media voices (Christians et al., 2009) or giving ordinary people opportunities to express opinions (Gil de Zúñiga and Hinsley, 2013). This, therefore, raises pertinent questions explored in this study: how prevalent are private citizens in day-to-day reporting? Where do journalists obtain these ordinary voice contributions? What role do private citizens fulfil in the news? As this study analyses news website output, these questions are addressed alongside broader interrogations of how citizen contributions are obtained and used within online news production cycles, typically associated with heightened time pressure, reduced newsroom resources and all-day publishing expectations (Paulussen, 2012).

Data from five news websites is explored through qualitative content analysis. For holistic understanding, we must analyse the actions involved in sourcing and story assembly, as well as final outputs. Therefore, a practice-based theoretical approach (Ahva, 2017), with its emphasis on everyday routines, is appropriate. In particular, structuration theory (Giddens, 1984; Stones, 2005) and the interaction between structures and agency is a useful framework to consider how and why private citizens are legitimised and utilised in news coverage, how they fit into the news "system", and how such a social system is continually reproduced through the combination of structural forces and journalists' actions. In particular, Giddens' conceptualisation of rules and resources (signification, domination, and legitimation), and the enabling and constraining nature of structures, support the discussion.

The study is based on health policy and healthcare news among five mainstream websites in Ireland. Although focusing on health suggests niche coverage, the data is a subset of overall general newsroom output; $58 \%$ of stories were by general reporters (the remainder either political or health correspondents), and coverage is limited to policy dimensions rather than biomedical or lifestyle angles. The article opens with existing literature on the public as a source and evolving newsroom systems before describing the study's methodological approach. The discussion comprises four elements: i) the prevalence of private citizens; ii) the origins of private citizen contributions; iii) the role private citizens fulfil in news; iv) specific issues related healthcare coverage. As well as the primary focus on citizen voices, the study also contributes to the literature on journalistic sourcing practices in online news. 


\section{The public as a source}

Analysis of news values suggests personalisation and human-interest angles can be steering forces to explain why journalists pursue certain stories (Gans, 1979), either for entertainment or something darker and dramatic (Harcup and O'Neill, 2016). Voices representing the public feature in various forms (Lewis, Inthorn and Wahl-Jorgensen, 2005), with Bosch identifying three categories: i) people with certain pedigrees or affiliations acting as representatives (eg politicians or interest groups); ii) people included due to their experiences, usually a personal/dramatic relationship with an issue; iii) people sourced by their supposed "ordinariness", such as vox pops (2013, p. 219). Although Lewis et al (2005) appear to support vox pops as a space for individuals to communicate in their own words, some are more sceptical. As well as questions about representativeness (Beckers, Walgrave and Van den Bulck, 2016) and unfair expectations (Myers, 2000), Kleemans et al suggest passers-by provide journalists with an "easy way out" for inclusion, arguing that vox pops typically appear as additional content alongside coverage of an existing news event, rather than providing citizens with authoritative platforms to direct media towards new topics (2017). The rate of private citizen use can vary by topic (Dimitrova and Strömbäck, 2009) and gender with, for example, women more likely to appear in health coverage (Ross, 2007). Among health stories more generally, Hinnant et al (2013) highlight the various roles journalists assign exemplars, such as humanising rare diseases, showing audiences how policy decisions may affect them, or simply attracting readers. When asked about the merits of different sources, journalists highlighted the "humanness" of exemplars and families, compared with the apparent detachment of expert sources such as politicians or academics (Hinnant, Len-Ríos and Young, 2013). In their Canadian study, Rachul and Caulfield (2015) find high levels of patient perspectives, noting how narratives are typically built around improved service access; the government-letting-citizens-down narrative is common. This clear "patient-access ethos" supports the expansion of treatments and funding but can diminish evidence regarding efficacy and safety. Similarly, the dominance of patient-access concerns are echoed in Hind et al's (2011) research examining coverage of the trastuzumab breast cancer drug.

Human-interest stories typically grant roles to individuals as case studies or exemplars: Bosch cites Brosius and Bathelt, describing such coverage as illustrating "causes, importance, and consequences of the problem from the unique perspective of an individual" to represent broader phenomena $(2013$, p. 218). However, concern arises about this supposed representation and exemplification effects, whereby a small number of experiences are "the basis for the perception of a larger body of like occurrences" (Zillman, 2008, p. 20). Elsewhere, the ethical nature of using such cases studies and "the tyranny of the anecdote" are issues with which journalists must grapple (Craig, 2003). Although some exemplars represent the population, Zillman argues, others may not, and their inclusion "seems more inspired by dramatic and ideological slants" than impartial reporting (2008, p.21). Yet some studies highlight how stories with dramatic or emotional dimensions actually reduce news coverage "knowledge gaps", addressing some failings of the detached, official-source model (Bas and Grabe, 2013). Granting "storyteller prestige" and validity to citizens' experiences (Kunelius and Renvall, 2010) can also demonstrate how ordinary people are able to form reasonable arguments and challenge official definitions, if given the chance (Robinson, 2009) - but journalists must extend that role of primary or contesting definer (Hall et al., 1978; Carlson, 2009; Splendore, 2017) beyond official sources.

Concerns around official sources relate to information subsidies (Gandy, 1982), "churnalism" (Lewis, Williams and Franklin, 2008; Jackson and Moloney, 2016), and generally passive reporting. Although information subsidy use in news is not a new phenomenon (Gandy, 1982; Macnamara, 2016), political communication's evolution in recent decades is increasingly professionalised and mediatised (Mancini, 1999; Mazzoleni and Schulz, 1999) engaging public relations methods (Davis 2010). Crucially, this is not limited to party politics, but also NGOs and advocacy groups (McNair, 2004), while Hallin and Briggs (2016) refer to the "co-production" of 
health and biomedical news involving a series of stakeholders and communications professionals. For non-journalist actors, adopting media logic (Altheide and Snow, 1979) involves adjusting strategies to accommodate how the media functions, specifically newsroom practices (Esser, 2013), thus drawing attention to the channels through which journalists source news. This evolution of mediatised practices comes amid newsroom cutbacks and increased temporal pressures on journalists in digital spheres, highlighting the balance of power with sources and questions over who defines the news (Carlson, 2009), as well as how online networks may alter daily newsgathering practices (Lecheler and Kruikemeier, 2016).

Online news systems: new structures, new voices?

From sourcing perspectives, the networked nature of online communication technologies provided the tools to potentially reimagine the relationship between the public and journalists. Bruns had suggested that as digital media producers' limitations on physical space, time, and bandwidth ease, scope existed for heightened coverage of "marginal" stories and more "multi-perspectival" approaches (2005), an optimistic narrative echoed in radical visions of the internet's potential, since evolving into more deconstructive accounts (Ahva and Steensen, 2016). Any increase of private citizens in news over the past two decades has sometimes been associated with a more generally public-minded and inclusive relationship with audiences, but these actors may not challenge elites' dominance in terms of roles and credibility within the stories (de Keyser and Raeymaeckers, 2012). While journalists may recognise the online potential for a wider range of voices, this may not necessarily translate to altered behaviour (Fortunati et al., 2009). Lechler and Kruikemeier (2016) find the research into new media sources contradicts expectations; crucially, they conclude that online techniques have not led to more diverse or public-centred reporting, while social media is often associated with soft news stories (Broersma and Graham, 2013). Yet, for Kleemans et al, it is not a surprise that sourcing routines are difficult to alter: "Changing routines means changing the very core of the profession. This takes time and requires a feeling of necessity" (2017, p. 179).

There is little doubt that journalists adapting to converged newsroom dynamics and digital outputs face challenges associated with diminished labour conditions, increased workload and multiskilling, immediacy, and increased desk work, leading to concerns about quality (Paulussen, 2012). Yet while circumstances change, the reinforcement of existing systems and journalism's ongoing resilience is well highlighted (O'Sullivan and Heinonen, 2008; Larsson, 2012; Menke et al., 2018). Nevertheless, even gradual change contributes to journalism's role as an institution (Ryfe, 2006; Eide and Sjøvaag, 2016). The institutional nature means journalism can be considered an ongoing social system, continually reinforced through its actors' actions and how they interpret structures, ideas at the core of structuration theory. When Giddens' (1984) work on systems and structuration is applied to journalism studies, it is apparent how the structures and individual decision-making and agency of reporters and editors combine to produce news production patterns (Larsson, 2012; Mare, 2014). In sourcing, this duality of structure (Giddens, 1984) - the combined, not distinct forces of structure and agency - can manifest in particular ways, as reporters seek easily accessible sources (Usher, 2013) and those with perceived legitimacy (Schneider, 2013). Furthermore, this resonates with the "availability" and "suitability" factors in source selection (Gans 1979), also categorised as knowledge, credibility, willingness, and timely communications (Meer et al., 2017). This reminds us that journalists draw on both ideological and pragmatic motivations when sourcing; news values, normative goals, and structural constraints combine to affect not just who makes it into the news, but how their contributions are used. This is a valuable way to conceptualise news as a social system, comprising a host of physical and psychological factors and influences both internal and external to journalists (Shoemaker and Reese, 2014). In structuration, the rules and resources are what steer - and ultimately reproduce - social systems: Giddens describes the rules of signification (meaning), legitimation (norms) and the resource of domination (power) as perceived structural forces shaping how actors behave. For this study, each structural force is linked to journalistic sourcing and an associated research question (Table 1). Structuration also provides a useful vernacular to explore the dynamics of the structures and decision-making associated with 
news sourcing, and the reflexivity involved. Giddens says most structural sociology is inspired by the idea that society's structural properties form constraining influences; however, structuration proposes structures as both enabling and constraining, opening certain possibilities of action while restricting others $(1984$, p.169). This facilitates a useful discussion of source use and advantages/disadvantages of the patterns identified in this study, particularly against the backdrop of online publishing and what it affords and restricts.

\begin{tabular}{llll}
\hline & Description & $\begin{array}{l}\text { Journalistic sourcing context } \\
\text { related to this study }\end{array}$ & Research question \\
\hline $\begin{array}{l}\text { Signification } \\
\text { (rule) }\end{array}$ & $\begin{array}{l}\text { Meaning given to work by } \\
\text { agents }\end{array}$ & $\begin{array}{l}\text { The goals of journalists and the } \\
\text { stories/sources they choose to } \\
\text { amplify }\end{array}$ & $\begin{array}{l}\text { How prevalent are private } \\
\text { citizens in day-to-day reporting? }\end{array}$ \\
\hline $\begin{array}{l}\text { Domination } \\
\text { (resource) }\end{array}$ & $\begin{array}{l}\text { Power/resources (both } \\
\text { economic and authoritative) }\end{array}$ & $\begin{array}{l}\text { Newsroom cutbacks and } \\
\text { increasing pressure on reporters } \\
\text { to find stories amid all-day } \\
\text { publishing cycles }\end{array}$ & $\begin{array}{l}\text { Where do journalists obtain } \\
\text { private citizen contributions? }\end{array}$ \\
\hline $\begin{array}{l}\text { Legitimation } \\
\text { (rule) }\end{array}$ & $\begin{array}{l}\text { The norms which are } \\
\text { maintained within the system } \\
\text { through actions }\end{array}$ & $\begin{array}{l}\text { The composition and structure } \\
\text { of stories. The actors who } \\
\text { dominate stories and are } \\
\text { granted legitimacy }\end{array}$ & $\begin{array}{l}\text { What role do private citizens fulfil } \\
\text { in stories? }\end{array}$ \\
\hline
\end{tabular}

Table 1: The rules and resources (Giddens 1984) used in this study alongside the associated research questions

Overall, existing work into journalists' use of ordinary citizens as sources point to normative desires for such individuals to be legitimised and granted media platforms, taking on roles as influential, informed contributors to public debate. However, as technology has advanced, despite initial optimism about democratisation, it remains unclear the extent to which private citizens are amplified. This leads to RQ1: How prevalent are private citizens in day-to-day reporting?

Elsewhere, long-established journalistic pressures such as speed may be amplified amid online publishing cycles and reduced resources. This is particularly pertinent alongside the growing input of public relations and professionalised media strategies from stakeholders seeking to influence coverage. Against such a backdrop, questions arise about how journalists may adjust their practices to fulfil the normative desire of including citizen voices, leading to RQ2: Where do journalists obtain ordinary voice contributions? This is underexplored in empirical research to date but provides a valuable insight into sourcing practices in the online era.

Finally, while journalists are drawn to dramatic individual stories and the ability for exemplars to humanise events, such patterns raise concerns about exemplification effects or anecdote-driven coverage. Similarly, vox pops also raises concerns, further highlighting why it is important to analyse how private citizens are portrayed. This leads to RQ3: What role do private citizens fulfil in the news?

\section{METHODOLOGY}

Healthcare has functioned as a useful subject-specific lens through which general journalistic practices can be examined (Bard, 2017; Holland, 2017; Stroobant, De Dobbelaer and Raeymaeckers, 2018). In Ireland, many structural and administrative concerns regarding the health system (Burke, 2009) manifest in daily coverage. Healthcare, therefore, offers a basis upon which to consider the diverse stakeholders, power dynamics, journalistic routines and sources used when 
covering an issue at the core of the state-citizen nexus. The data, from five mainstream Irish news outlets (Table 2), was gathered over 14 weeks (two seven-week periods, three months apart). The sample included stories related to Irish healthcare and health policy, obtained using RSS feeds and keyword searches (manually reviewed for relevance). The parameters of a health policy story was based on whether it answered either question: (i) Does the content deal with an issue that could directly impact on the health/health service policy/conditions/treatment of Irish residents? (ii) Does the state - in the political or legislative sense - have any role? This meant stories about scientific and biomedical developments or nutrition/lifestyle-related content were excluded unless there were tangible policy dimensions.

\begin{tabular}{llccc}
\hline \multicolumn{1}{c}{ WEBSITE } & $\begin{array}{c}\text { ALEXA } \\
\text { RANKING* }\end{array}$ & FORMATS & TONE & $\begin{array}{c}\text { \#STORIES IN } \\
\text { SAMPLE }\end{array}$ \\
\hline IrishTimes.com & 3 & $\begin{array}{c}\text { Print and } \\
\text { online }\end{array}$ & Broadsheet & 288 \\
\hline Independent.ie & 1 & $\begin{array}{c}\text { Print and } \\
\text { online }\end{array}$ & $\begin{array}{c}\text { Mid-market/ } \\
\text { Broadsheet }\end{array}$ & 286 \\
\hline BreakingNews.ie & 8 & Online only & Mid-market & 174 \\
\hline TheJournal.ie & 5 & Online only & Mid-market & 89 \\
\hline IrishMirror.ie & $6^{* *}$ & $\begin{array}{c}\text { Print and } \\
\text { online }\end{array}$ & Tabloid & 59 \\
\hline
\end{tabular}

Table 2: The five websites selected.

* Irish Alexa rankings for news websites at time of data analysis in 2016

**Alexa shows Mirror.co.uk, the UK parent organisation website, not the Irish domain IrishMirror.ie

An innovative qualitative content analysis was developed to establish links between daily journalistic activities and output. Some have argued that content analysis alone is insufficient to determine journalistic practices (Reich, 2006), but inspiration was taken from Altheide's (1987, 1996) work on ethnographic content analysis/qualitative document analysis, which allows the researcher to look beyond the media text. In this instance, the content analysis had two stages: (i) to record the sources present; (ii) then trace back each source contribution to determine where the information originated. This second stage required search engines, listening to radio show recordings, searching social media and parliamentary transcripts, as well as drawing on cues within the news text indicating its origins, such as "speaking exclusively to this news organisation", or "according to a statement from the organisation" (approximately 7.5\% of searched content could not be traced). Combining the data from these two stages generated results not possible from traditional content analyses focused solely on news content. Source presence was measured in three ways: (i) whether a source group was present or not, and who was the first source referenced; (ii) the number of appearances of each source category within the story (eg $3 \mathrm{x}$ politicians); (iii) the quantity of coverage, based on measuring word count of source contributions.

Following the content analysis, an interview was carried out with the minister for health at the time of data collection, Leo Varadkar (during the 2017 interview, Varadkar was minister for social protection. Later in 2017 he became Ireland's prime minister). The focus was news production and coverage more broadly, but only material related to private citizens is applicable here. Interview contributions from three journalists are also briefly cited in the discussion: the interviews were conducted as part of a broader study on digital news production and only short segments are relevant to the data here so their representativeness should not be overstated. 


\section{RESULTS \& DISCUSSION}

The results and discussion that follow are structured around four topics: i) the prevalence of private citizens; ii) the origins of contributions; iii) what role private citizens fulfil, and iv) some issues associated with healthcare coverage specifically.

\section{Prevalence of private citizens}

The occurrence of private citizens in news reports varies between titles. Proportionally, the tabloid Irish Mirror uses the highest rate (43\% of stories including a private citizen), reinforcing the traditional commitment of tabloid titles to human-interest angles (Harcup and O'Neill, 2001). Conversely, IrishTimes.com (8\%) and BreakingNews.ie (4.5\%) use the lowest proportion of citizen contributions (Independent.ie: 21\%; TheJournal.ie: 16.5\%). BreakingNews.ie and TheJournal.ie are both net-native but these results demonstrate how they are no more likely to include citizen perspectives than legacy newspaper-title brands.

Overall, private citizens appear in 115/896 news texts, making them the fifth most common source (Figure 1), behind politicians, state agencies, trade union/representative groups, and medical professionals. The dominance of these elite voices aligns with existing research highlighting journalists' reliance on establishment figures. Although trade unions were historically marginalised in news (Philo, 1990), previous findings suggest unions are among Irish journalists' staple institutional sources (Cawley, 2012). Given this potential tension, this paper considers private citizen perspectives as those based on direct individual contributions rather than indirect unions or political representations.

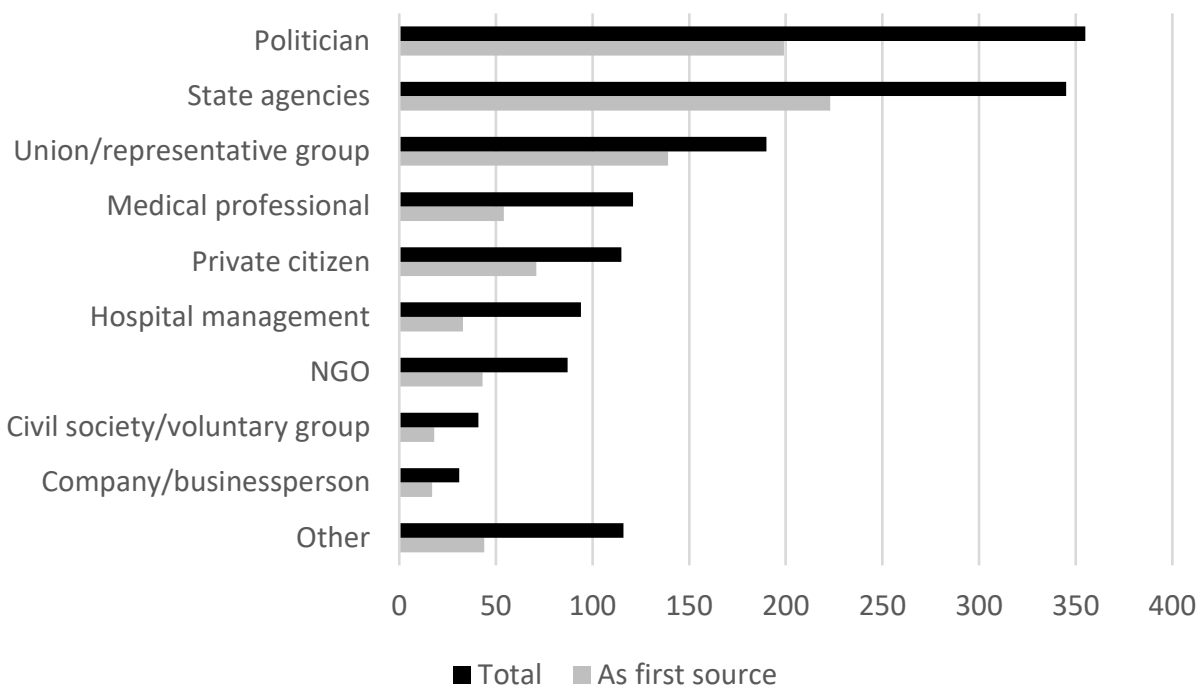

Figure 1: The number of stories in which different sources appear, and the number in which they are the first source used. The "other"category includes anonymous sources, religious figures, academics, celebrities, solicitors, and judges.

Figure 1 also shows the most prevalent first sources, as analysing the quotation/contribution structures is an effective way of looking at opinion-leading sources (Kolmer, 2008). Private citizens 
are the first source in 71/115 stories in which they appear (62\%), suggesting that when they are used, they take on a relatively influential role in shaping the story. However, as Figure 2 illustrates, private citizens are rarely the only source, instead frequently "diluted" by other voices. It is not possible to determine whether these accompanying sources were supportive or contradictory, but their presence suggests journalists believe further contributions are needed to strengthen or legitimise a story. Concerns around single-source stories are well-established (Franklin, Lewis and Williams, 2010) so it should not necessarily be problematic that private citizens appear alongside other sources; for example, in healthcare, there may be a right of reply required by state agencies. Nevertheless, when compared with other source groups, a pattern is apparent, raising questions about who is "reliable" or has the legitimacy (Giddens, 1984) to be quoted alone. As Figure 2 shows, trade union groups were frequently the sole source, in almost half of the cases, while officials like politicians and state agencies also often provided information subsidies serving as the sole content in reports. These patterns also align with the distinction of "source actors", whom journalists consider reliable enough to use without further investigation (Couldry, 2010). One reporter (TheJournal.ie) reflected on trade unions' privileged position, aligning it with journalists' desire for worker-focused angles: "I think news organisations might say, 'right I'm actually helping the actual workers here by saying what the union are wanting me to say', and in that sense they're probably ticking a couple of boxes, and that's why they tend to get covered." This echoes Giddens' credibility criteria (1984) and the rationalisation of action agents use to provide reasons for what they do. Yet this univocity raises the tension present between private citizens and how they are sometimes represented through a single voice from a "legitimate" sources, potentially at the expense of more authentic plurivocity or layered contributions.

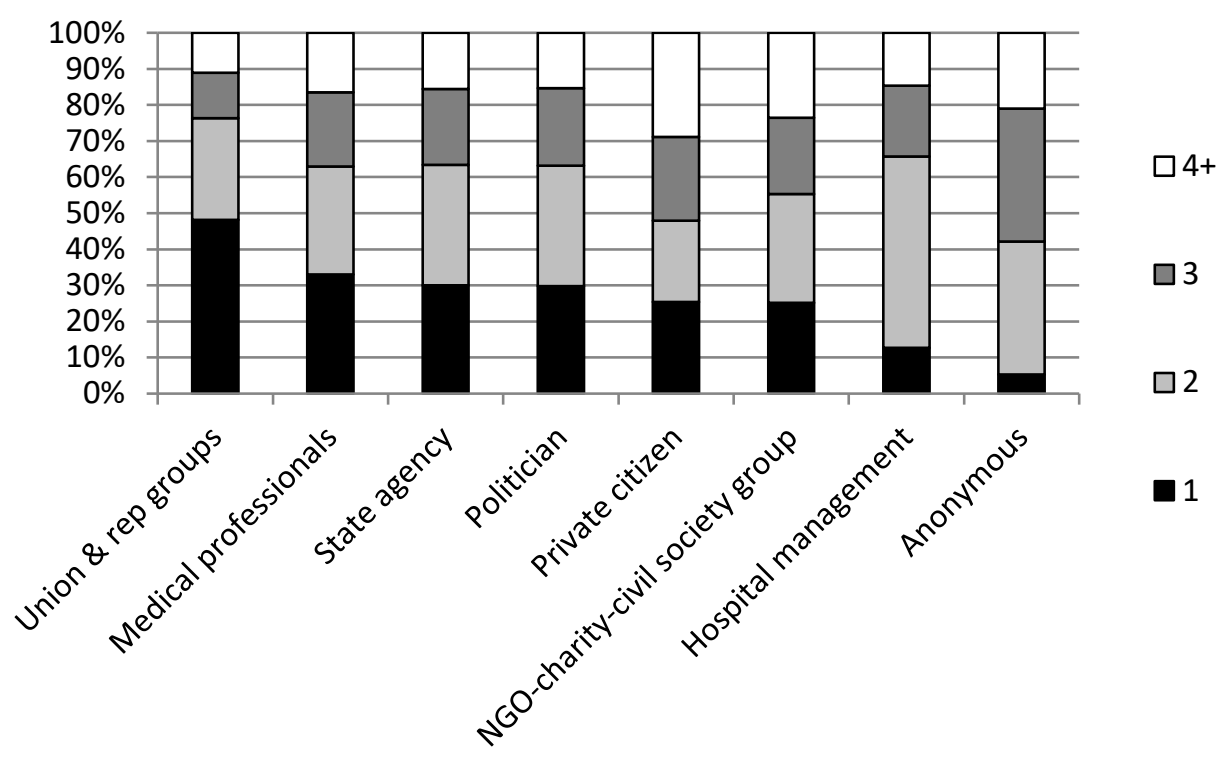

Figure 2: The number of stories in which each source group is present as the only source (1) and alongside other sources $(2,3,4+)$. Private citizens are the only source used in $25 \%$ of the stories in which they appear, but in almost $30 \%$ of stories, they appear as one of four or more sources.

The voices of "ordinary" women?

Among all sources, the male:female ratio of sources is $2: 1$, associated with the individual men in key positions of power, such as the minister for health, the chief executive of the Health Service Executive, and the then general secretary of the Irish Nursing and Midwives Organisation trade union who were frequently quoted. However, this ratio is reversed within the private citizen category, with $67 \%$ female contributors. Many of these stories portray women in the role of 
concerned relatives, making passionate pleas for family members, or describing traumatic events, such as "Desperate mother begs Health Minister for life-changing spinal surgery for daughter (13)" (Independent.ie) or "Mother of 7-year-old girl with cerebral palsy says apology from hospital 'too little too late"” (TheJournal.ie). Elsewhere, numerous pregnancy-related anecdotes continually position women as carers, mothers, and homemakers (Tuchman, Kaplan Daniel and Benet, 1978). The repeated narratives and portrayals of women in such manner is a challenge for journalists, touching on key tensions between the merits of individual stories and broader trends; what appears suitable and legitimate for one story - such as reporting the grievances of a mother - can have broader ramifications when stereotypes are repeated. Giddens (1984) refers to the unintended consequences of action in social systems, evident here through the reinforcement of stereotypical gender roles. While highlighting dramatic stories, if the same voices are continually heard in a similar manner, or excluded, questions remain over how news content aligns with democratic ideals about multiple perspectives (Christians et al., 2009). Such victimised coverage of "ordinary" women in this study, who are often making emotional family-based contributions, contrasts with the seemingly calmer, more detached men dominating the official, elite level of coverage, echoing the distinctions articulated by journalists when reflecting on source selection (Hinnant, Len-Ríos and Young, 2013). The results also suggest that ordinary men are less likely to interact with journalists to fulfil this domestic role, which may indicate concerns about exposing vulnerability or simply reflect a smaller number of men in such primary carer roles.

\section{Origins of private citizen contributions}

Understanding how journalists obtain source contributions can be methodologically challenging for traditional content analysis, but this study's approach can provide some fresh insights. Journalists are obtaining the contributions of private citizens through three main channels: original interviews, other media/news sources, and information subsidies. These results are based on space provided to the sources (measured using word count), and Figure 3 shows these sourcing channels alongside politicians for comparison.

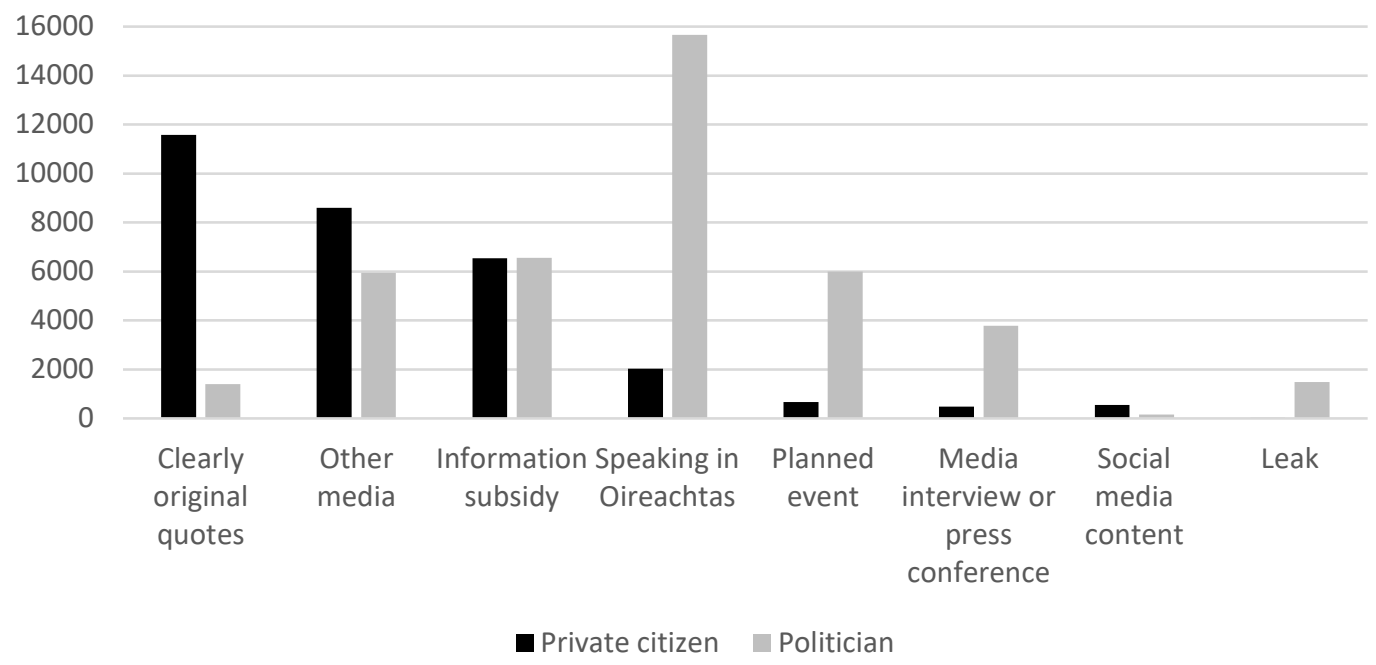

Figure 3: The origins of content for media contributions from private citizens and politicians, measured using word count

Original quotes were coded as such if it was clear that the journalist directly obtained these contributions (eg, references like "speaking to Independent.ie"), however, this may not capture 
informal and less transparent roles of PR in establishing journalist-source connections. The "other media" category is discussed further below. The third most prevalent category is from information subsidies, primarily various types of reports; this applies to both reports such as the health service watchdog report, which may contain private citizen perspectives in official findings, and NGO reports. Some advocacy groups include case studies in reports, providing human-interest angles which journalists often reproduced . Examples include "Lupe's experience" in Amnesty's She is not a Criminal report about Ireland's previously restrictive abortion laws, or the stories of individual Malawian and Filipino migrant workers suffering poor working conditions in the homecare sector (profiles included in material issued by the Migrants Rights Centre Ireland). This suggests advocacy organisations are embracing media logic (Altheide and Snow, 1979) and drawing on media-friendly communication strategies, adopting forms and content which resonate with journalists' demands. This points to what Giddens refers to as a dialectic of control, in which there are regularised relations of autonomy and dependence between actors in social interactions: "All forms of dependence offer some resources whereby those who are subordinate can influence the activities of their superiors" (1984, p. 16). This resonates with the "tug of war" (Gans, 1979; Carlson, 2009) of journalist-source interactions; journalists may have the ultimate power over publication, but their circumstances often contribute to a reliance on available material. Online specifically, open-ended news gaps may intensify pressure, meaning journalists are eager for content to quickly and easily repackaged. The domination resource (Giddens 1984) becomes relevant, raising questions about newsroom resourcing and expectations surrounding all-day publication. The use of information subsidies is nothing new, but crucially, the pattern has evolved and it is not just traditionally influential official sources benefiting, as routine and PR sourcing may be advantageous to representative groups, private citizens and NGOs. This suggests that certain organisations with effective media strategies can find their voice amplified via a media which appears sometimes to be in a secondary position, in desperate need of content to fulfil the perceived demands of all-day publication. This use of secondary content could be seen an enabling force, by diversifying contributions, but there are constraining elements, too: although this may lead to a literal diversification of voices, it is ultimately passive reporting and such reliance on information subsidies is concerning.

\section{Private citizens and recycled media}

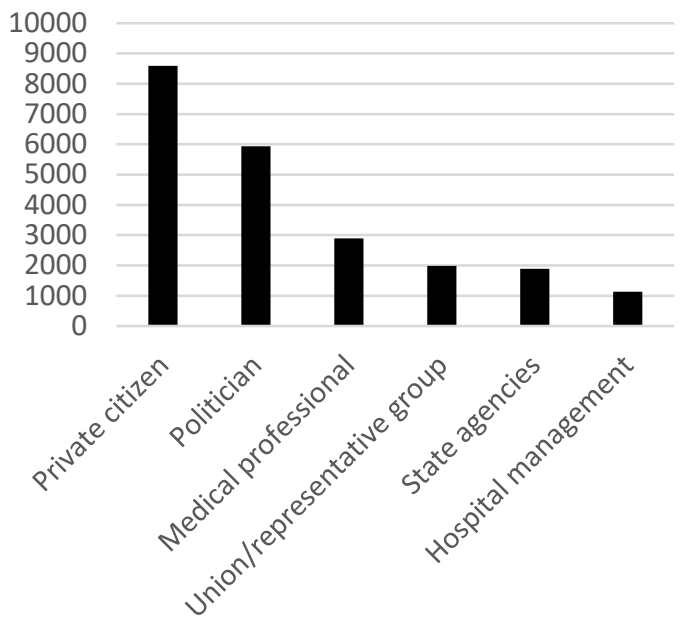

Figure 4: The content traced back to "other media reports", categorised by speaker, showing how private citizens benefit from this channel. The results are based on word count. 
Private citizens are the source group whose contributions are most frequently repurposed or "cannibalised" (Phillips, 2011) from rival outlets (Figure 4), primarily radio programmes. One example was a man who found confidential hospital records on the street and appeared on a local radio show: this story was picked up by all five outlets, all including quotes from the original phonein caller. Similarly to case studies within information subsidies, such recycling of content presents a difficulty when assessing the trend from normative journalistic perspectives, touching on the enabling and constraining nature of structures within the news production system. On one hand, it presents a platform and opportunity for wider dissemination of stories which may be in the public interest, while helping journalists achieve their desire for real-life contributors. However, it ultimately reinforces and normalises a passive culture of news reporting, and a bricolage approach of pre-existing materials, which may be problematic if coming at the expense of original newsgathering. Accessing quotes in this convenient and low-cost manner fulfils the "availability" sourcing criteria, and the fact they are published/broadcast elsewhere, and contain dramatic testimony, suggests credibility or suitability (Gans 1979). Such passive sourcing practices also highlight the influence of Giddens' structural resource of domination which, in this study (Table 1) relates to control and resource allocation in newsrooms alongside, cutbacks and heightened pressure to which journalists must adjust. These cannibalising content trends may indicate a further drop in the allocation of resources (Giddens 1984) to editorial departments, as journalists seek to publish continuous all-day updates amid staffing pressures. Regarding legitimation, it also suggests a redefinition or readjustment of what constitutes acceptable sourcing behaviour for professional journalists wanting to tell individuals' stories but who do not have the time, specialised skillset or opportunity for more original research.

Elsewhere, this study supports the somewhat-muted influence of social media as a source: just two stories using private citizens appear to be triggered by social media. The first, "Women are tweeting Enda Kenny [the Irish prime minister at the time] about their periods in a bid to highlight abortion rights in Ireland" (IrishMirror.ie) was based around a trending Twitter hashtag regarding reproductive rights. The second, "Second 100-year-old woman left on a hospital trolley for 25 hours" (IrishTimes.com) was based on a Facebook post by a patient's relative. It was, of course, not possible to account for reports in which social media was perhaps the starting point for a tipoff, but was not traceable.

\section{How are private citizens being presented?}

One concern regarding citizen voices extends beyond the quantification of appearances and relates to their role in news reports. Table 3 shows that in 109/115 stories, private citizens were present because of their direct experiences, subdivided into case studies illustrating an ongoing story; part of a process, such as a watchdog report or inquiry; or whether their experience forms the basis and starting point of the story. Private citizens as detached observers or commentators, typically in a vox pop or contributor to debate, was very low.

$<$ Table 3 here $>$

While highlighting individuals' concerns offers the person a platform, the dominance of individuals with direct experience is worth considering. In many cases, this can be linked with citizens in victimised, powerless roles, whether suffering at the hands of medical conditions, public services, or often both. This contrasts with alternative roles as an informed, empowered contributor to civic debate, and can be linked to the rules of legitimation (Giddens, 1984), and how journalists portray their sources and to whom they speak. Another concern relates to highlighting an individual's story in such a manner and the exemplification effects theory (Zillman, 2008). However, for journalists, such approaches provide opportunities to personalise a story, and one journalist from TheJournal.ie 
refers to the relatability or relevancy which presenting an exemplar offers: "People are so used to hearing there is, 500 people on [hospital] trolleys, but if you've spoken to a person down on the trolley, it's much more relatable. It's like, 'oh my God, she's just like my granny'. We always try to incorporate the personal story if we can". The desire to make something "relatable" has normative undertones, but there may be something more pragmatic at play, too, as they add: "The personal story always sells better and it's a way of getting people interested and to care." A second journalist from TheJournal.ie mentions how audience analytics indicate that stories built around humaninterest cases "perform" well online, adding that stories about specific health conditions, in particular, can benefit from citizen voices: "They perform much better when people hear directly from somebody affected by something, and so it's definitely something that's encouraged both because it looks better, and because it's what people want to read more." This appreciation of stories' performance may be indicative of the editorial side's acceptance of market forces (Cornia, Sehl and Nielsen, 2018), also reflecting the audience's heightened influence, as well as a suggestion that a story's value is tied to popularity. This desire for popularity, and engaging the public, indicates how journalists' ambition might combine both market values and professional ideals (Pihl-Thingvad, 2015). The journalist adds that personal voices might be used more in weekend or longer features, saying "in the day-to-day news cycle you're doing whatever the news story is. It's not always possible to talk to somebody affected", even if desired. Constraints of publication demands will, therefore, influence sourcing practices as information that is easily available - and perhaps the people who have existing, perceived legitimacy and can be quickly verified - are further amplified.

\section{Human interest stories and healthcare}

As the use of private citizens can vary by topic, the following section examines three aspects of healthcare coverage: (i) the implications of human-interest case studies from a government perspective; (ii) coverage of vaccine fears; (iii) the use of individual testimony to effect change.

As highlighted, private citizens primarily appear because of their dramatic personal experiences rather than as detached commentators. While publishing such dramatic, subjective stories highlights individuals' circumstances, it may have implications for healthcare resource allocation or public understanding of rationalisation of funding. In the Irish context, when asked about the familiar narrative of human-interest stories, the former minister for health Leo Varadkar explains that it puts those in authority in difficult positions: "Definitely dealing with individual cases was the hardest thing to do [as minister], because they're human, they're real... [The public] can see this person, they could think this person could be somebody I know, or it could be somebody's sister. That made it really hard." A traditional adversarial vision might suggest that anything presenting difficult situations for politicians means the media are fulfilling their watchdog role, but journalism's societal obligation must surely extend beyond individual cases. Aside from the personalised and often emotive nature of such coverage, he suggests "very often it wasn't the full story", but any official is limited in their response:

While an individual could go on the media with their case, you could never go back [and give the facts]... First of all, you'd be violating all sorts of privacy and data protection issues if you did, and secondly, even if you did, you'd probably lose anyway, because you'd be attacking the person who's in tears.

Varadkar elaborates by raising concerns around media attention bringing focus on specific issues or individuals, meaning "resources may be devoted towards that particular drug, that particular condition, that particular waiting list, that particular place in the country or region". Such coverage can sometimes make situations worse, he claims, as resources are deployed "to respond to negative publicity or political demands rather than what makes sense objectively". This aligns 
with well-established concerns regarding the democratic repercussions of the mediatisation process (Mazzoleni and Schulz, 1999), and how media coverage could potentially distort decision-making, in particular regarding the funding of drugs as the patient-access ethos typically overshadows costs and other considerations (Rachul and Caulfield, 2015).

The journalist from the tabloid Irish Mirror acknowledges some of this complexity; referencing the funding of certain drugs, they say that people are clearly suffering and there may be something available to help so "in that sense there is something valuable in highlighting these stories ... but you do have to consider the other side of the coin: that the government can't possibly fund all these treatments. It's not feasible, it's not realistic." They add that when doing a story like this, "it's important to think, 'well, is it truly fair to say that the government should be funding this? ... Is it realistic to say it's a disgrace?'" This captures the journalist's reflexive monitoring of actions (Giddens, 1984), exemplifying how professional news values may clash with the need for a more rationalised debate. It also suggests the journalists' social responsibility extends beyond simply highlighting potential injustices of individuals' stories, instead seeking and weighing up competing arguments. The influence of newsroom-centric news values in steering and potentially skewing coverage towards individual stories (and perhaps omitting other factors) is arguably a systemic issue in news coverage, driven by existing norms and cultures that permeate and are continually reproduced in newsrooms.

Another concern regarding the dissemination of individuals' experiences is the social responsibility of providing media coverage which may have dangerous public health repercussions. The HPV vaccine, offered to teenage girls in Ireland to help prevent certain cervical cancer strains, was the subject of four stories, all highlighting fears about the vaccine's alleged effects, despite most experts not supporting concerns. Consequently, the presence of such oppositional parents' opinions in coverage (three stories included mothers' contributions) raises questions about whether it is civically responsible for such voices, regardless of how passionate their convictions, to be shared and granted "storyteller prestige" (Kunelius and Renvall, 2010). The former minister for health Varadkar highlights his concern with vaccine critics, recalling the MMR-autism problem of the 1990s (Smith et al., 2008) saying he was "seeing this happening again". He said he tried not to dismiss the parents' concerns about the HPV vaccine - "their daughters clearly did have problems" - but his fear was that whatever problems the girls were suffering from was not being addressed if the emphasis remained on vaccines. Such coverage concerns align with the "tyranny of the anecdote" (Craig, 2003): there was a correlation between the growing public concerns about the HPV vaccine and a decline in its take-up in Ireland: in the 2014-2015 school year, the take-up rate was $87 \%$, dropping to $72 \%$ in $2015-2016$, and by 2017 it was down to $50 \%$.

Despite concerns about anecdotes and exemplars, the authentic experiences of patients and other citizens cannot be dismissed, even if they are outliers. A watchdog (Hiqa) report into baby deaths in Ireland's Midlands Regional Hospital Portlaoise was the single news event garnering most coverage $(n=120)$. In May 2015, Hiqa published its report detailing the circumstances of five newborn deaths in Portlaoise; it found no congenital problems, citing "other factors" leading to the babies' deaths. The report highlighted problems with HSE resourcing, poor management and risk assessment, and an alleged cover-up. Parents contributing to the report also highlighted negative personal experiences; revelations of grieving mothers being told not to cry in public, babies' bodies squeezed into small metal boxes, and parents told of their baby's death in hospital corridors. Contrasting with the overall sample, private citizens were the group with most coverage in the Portlaoise stories, comprising $34 \%$ of the perspectives shared compared with $16 \%$ in the overall sample. This news event illustrates how private citizens can gain substantial coverage, challenging any assumption that official proceedings or source material lead solely to the presence of official voices. The graphic, emotive nature of parents' testimony presented clear angles on which newsrooms focused, and the information from the original report, press conferences and media interviews were also easily accessible, enabling extensive coverage. Through journalists using secondary source material, the parents became the story's definers, rather than being overshadowed 
by bureaucrats, politicians or technical language. While, as highlighted, this has implications for victimised portrayals of citizens, as well as gender considerations, one dimension cannot be underplayed: the ability for problems to be recognised through the shared experiences of these parents who act as a catalyst in effecting change. Varadkar, referring to the Portlaoise story, said: "That's where you have to give credit to very good journalism", referring to the original broadcast on the national broadcaster RTÉ which triggered the watchdog report. He added: "The fact that those kind of investigations, even though sometimes they're sensationalised, at least when they're not, they shine a light into things and force the system to respond." The idea of how journalists, in highlighting individual stories "force the system" to respond resonates with watchdog and accountability ideals. In this instance, the deaths warranted attention; this was not just a one-off, even if it was not representative of most new parents' experiences.

\section{CONCLUSION}

The results and discussion have provided an under-researched discussion of the link between daily sourcing practices and output, offering insights into how journalists obtain and use private citizen contributions in news reports. In line with previous research, private citizens do not have the same pervasiveness in coverage as more established, elite sources. This suggests the ongoing reproduction of the news system in which elite voices are centred and privileged, and "ordinary" voices are primarily used to illustrate issues in more relatable ways. When we do hear from them, they are often the first source suggesting a defining role, although their contributions are typically "diluted" by other sources. It is twice as likely that we hear from "ordinary" women than men, which may be problematic if reinforcing stereotypical domestic gender roles, thus also contributing to the reproduction of social systems in which women are portrayed as carers. Nevertheless, private citizen voices prevail as an important dimension of news coverage, thus suggesting an ongoing normative commitment to sharing human stories which remains an intrinsic part of the signification rule (Giddens 1984) and the meaning and motivation associated with daily journalism.

Understanding the origins of these private citizen contributions was one of the study's goals and we can see a split in sourcing practices. Firstly, a high level of active work prevails as journalists obtain original interviews with private citizen contributors. Secondly, there is a strong reliance on passive channels; tracing the origins of content demonstrated how widespread it is for private citizen contributions to stem from other media reports, typically radio, and information subsidies. The prevalence of these passive sourcing practices can be considered in light of the domination/resources structure about which Giddens writes and, in particular, how newsrooms adapt to temporal and staffing pressures of digital publishing. Reporters may be adjusting to these demands by drawing on existing media and information subsidies which provide quick, easy and low-cost access to public voices, while maintaining their normative and pragmatic commitment to including private citizens voices. Such sourcing behaviours can be linked to more general concerns about churnalism and the lack of time and autonomy journalists have, instead often becoming reliant on secondary material. The findings demonstrate that a passive approach to news reporting, and efforts to fill the perceived open-ended news hole, may benefit private citizens in terms of ensuring they appear in news coverage. However, this ultimately may be problematic for journalism's ability to function as an independent observer due to a reliance on easily available source material, thus reinforcing the enabling and constraining nature of both PR material and allday publishing cycles. Such trends perhaps indicate an adjustment of the news sourcing system, reinforcing the conceptualisation of journalism as an institution, adapting as it evolves. Despite early expectations surrounding social media's potential, this study finds it has had little influence as a sourcing channel, nor have online networks more generally led to fundamental democratic shifts in mainstream news content.

The roles assigned to private citizens in coverage also provides a lens through which we can understanding legitimation (Giddens 1984), how actors are portrayed, and who gets authoritative 
roles in the news. Almost all the instances of private citizen appearances are based on those talking about direct personal experiences, rather than detached commentators on policy or social decisions. Official sources retain the legitimacy that has always steered reporters, while private citizens are almost exclusively used to illustrate problems with existing policy positions and care standards. Citizens present because of their apparent ordinariness are almost wholly absent, apart from a tiny number of social media contributions demonstrating a "voice from the public". This indicates the scarcity of professional news spaces in which audiences not subjectively involved in an issue can comment on general policy and contribute, potentially deepening the portrayed binary between seemingly rational, detached experts and emotional, subjective citizens within journalists' sourcing activity.

From governance or policy perspectives, emphasising human-interest stories can be problematic if other considerations and perspectives are omitted, but media still functions as a powerful platform through which change can be effected. This is an inherent tension that permeates news coverage and may clash with the concerns regarding exemplification effects or the adverse consequences of mediatised policy arenas. However, news, by its nature, is associated with the outliers and the unusual; individual exemplars may not be representative, but their story remains accurate. Similarly, concerns around how women are portrayed must align with the fact that these are true, authentic stories from real people. It appears that the systemic nature of news production - with its routinised practices and normative goals - ultimately sees many established patterns reproduced despite digital changes.

One important limitation is the study's base in a small country, and the focus on health; this is a sector in which experiences are, by their nature, highly personal, emotive and sometimes indicative of life-and-death situations which may be associated with the high level of individuals sharing

personal experiences. Nevertheless, the policy framework underpinning any national health sector warrants public interest and input like any social or political issues, so the need for contributions from more detached non-elite stakeholders should not be overlooked. Despite this, focusing on any single area means nuances associated with other areas are not incorporated, so the generalisability of the results must be cautioned. Another concern is that the attention was on text-based stories: broadcasting sources may vary. Methodologically, it should be remembered that not all material was traceable to its original source, while the small number of interviews is a clear limitation. Given their focus lay elsewhere, and how it was never the intention to garner wide-ranging contributions on this specific subject, the interviews used here provide useful context and should be taken in that light.

Looking forward, there are still many aspects of the journalist/“citizen-as-source" relationship warranting further attention, such as more direct input from practitioners regarding their attitudes towards using private citizen contributions from passive channels, and how online publication expectations may affect what they consider acceptable practice. One other area not explored is how reporters obtain those contributions categorised as "original research", and it remains unclear whether networks of personal contacts and tip-offs, PR liaisons, sources contacting the media themselves, or even social media, are steering forces. In terms of social media, there are some interesting trends with hashtags such as \#journorequest and \#HARO (Help a Reporter Out) used by journalists seeking to speak to somebody with insight or experience about an issue. The effectiveness and practices involved in this process remain opaque and could benefit from research attention, likely through direct input from practitioners reflecting on their practices. 


\section{REFERENCES}

Ahva, L. (2017) 'Practice Theory for Journalism Studies', Journalism Studies, 18(12), pp. $1523-1541$.

Ahva, L. and Steensen, S. (2016) 'Deconstructing Digital Journalism Studies', in Franklin, B. and Eldridge II, S. (eds) The Routledge Companion to Digital Journalism Studies. New York: Routledge, pp. 25-34.

Altheide, D. L. (1987) 'Ethnographic Content Analysis', Qualitative Sociology, 10(1), pp. 6577.

Altheide, D. L. (1996) Qualitative Media Analysis. Thousand Oaks: Sage Publications.

Altheide, D. L. and Snow, R. P. (1979) Media Logic. Beverly Hills, CA: SAGE.

Bard, M. T. (2017) 'Propaganda, Persuasion, or Journalism? Fox News' Prime-Time Coverage of Health-Care Reform in 2009 and 2014', Electronic News, 11(2), pp. 100-118.

Bas, O. and Grabe, M. E. (2013) 'Emotion-Provoking Personalization of News', Communication Research, 42(2), pp. 159-185.

Beckers, K., Walgrave, S. and Van den Bulck, H. (2016) 'Opinion Balance in Vox Pop Television News', Journalism Studies, 9699(June), pp. 1-13.

Blumler, J. G. and Cushion, S. (2014) 'Normative Perspectives on Journalism Studies: StockTaking and Future Directions', Journalism, 15(3), pp. 259-272.

Bosch, B. (2013) 'Beyond Vox Pop: The Role of News Sourcing and Political Beliefs in Exemplification Effects', Mass Communication and Society, 17(2), pp. 217-235.

Broersma, M. and Graham, T. (2013) 'Twitter As a News Source', Journalism Practice, 7(4), pp. $446-464$.

Bruns, A. (2005) Gatewatching: Collaborative Online News Production. Peter Lang.

Burke, S. (2009) Irish apartheid: healthcare inequality in Ireland. Dublin: New Island.

Carlson, M. (2009) 'Dueling, Dancing, or Dominating? Journalists and Their Sources', Sociology Compass, 3/4, pp. 526-542.

Cawley, A. (2012) 'Sharing the Pain or Shouldering the Burden?', Journalism Studies, 13(4), pp. 600-615.

Christians, C. G. et al. (2009) Normative Theories of the Media: Journalism in Democratic Societies. Urbana, Illinois: University of Illinois Press.

Cornia, A., Sehl, A. and Nielsen, R. K. (2018) "'We no longer live in a time of separation": A comparative analysis of how editorial and commercial integration became a norm', Journalism.

Couldry, N. (2010) 'New Online News Sources and Writer-Gatherers', in Fenton, N. (ed.) New Media, Old News: Journalism and Democracy in the Digital Age. London: Sage Publications, pp. $138-152$.

Craig, D. A. (2003) 'The promise and peril of anecdotes in news coverage: An ethical analysis', Journalism and Mass Communication Quarterly, 80(4), pp. 802-817. 
Dimitrova, D. V. and Strömbäck, J. (2009) 'Look who's talking: Use of sources in newspaper coverage in Sweden and the United States', Journalism Practice, 3(1), pp. 75-91.

Eide, M. and Sjøvaag, H. (2016) 'Journalism as an Institution', in Eide, M., Sjovaag, H., and Larsen, L. O. (eds) Journalism Re-examined. Bristol: Intellect, pp. 1-14.

Esser, F. (2013) 'Mediatization as a Challenge: Media Logic Versus Political Logic', in Kriesi, H. et al. (eds) Democracy in the Age of Globalization and Mediatization. Basingstoke: Palgrave, pp. 155-176.

Fortunati, L. et al. (2009) 'The Influence of the Internet on European Journalism', Journal of Computer-Mediated Communication, 14(4), pp. 928-963.

Franklin, B., Lewis, J. and Williams, A. (2010) 'Newsmaking: Rules, routines and rituals', in Allan, S. (ed.) The Routledge Companion to News and Journalism. Oxon: Routledge, pp. 202 212.

Gandy, O. H. (1982) Beyond agenda setting: information subsidies and public policy. Norwood, N.J.: Ablex Pub. Co.

Gans, H. J. (1979) Deciding What's News. New York: Pantheon Books.

Gans, H. J. (2011) 'Multiperspectival news revisited: Journalism and representative democracy', Journalism: Theory, Practice \& Criticism, 12(1), pp. 3-13..

Giddens, A. (1984) The Constitution of Society: Outline of the Theory of Structuration. Berkley: University of California Press.

Gil de Zúñiga, H. and Hinsley, A. (2013) 'The Press Versus the Public', Journalism Studies, 14(6), pp. 926-942.

Hall, S. et al. (1978) Policing the Crisis: mugging, the state, and law and order. London: Macmillan.

Hallin, D. and Briggs (2016) Making Health Public. London: Routledge.

Harcup, T. and O'Neill, D. (2001) 'What Is News? Galtung and Ruge revisited', Journalism Studies, 2(2), pp. 261-280.

Harcup, T. and O'Neill, D. (2016) 'What is news? News values revisited (again)', Journalism Studies. Taylor \& Francis, pp. 1-19.

Hind, D., Wailoo, A. J. and Sutcliffe, P. (2011) 'Demands for "off-licence" access to trastuzumab (Herceptin): Content analysis of UK newspaper articles', Health Expectations, 14, pp. 38-47.

Hinnant, A., Len-Ríos, M. E. and Young, R. (2013) 'Journalistic Use of Exemplars To Humanize Health News’, Journalism Studies, 14(4), pp. 539-554.

Holland, K. (2017) 'Making Mental Health News', Journalism Studies. Taylor \& Francis, 0(0), pp. 1-19.

Jackson, D. and Moloney, K. (2016) 'Inside Churnalism: PR, journalism and power relations in flux', Journalism Studies, 17(6), pp. 763-780.

de Keyser, J. and Raeymaeckers, K. (2012) 'THE PRINTED RISE OF THE COMMON MAN: 
How Web 2.0 has changed the representation of ordinary people in newspapers', Journalism Studies, 13(5-6), pp. 825-835.

Kleemans, M., Schaap, G. and Hermans, L. (2017) 'Citizen sources in the news: Above and beyond the vox pop?', Journalism, 18(4), pp. 464-481.

Kolmer, C. (2008) 'Methods of Journalism Research - Content Analysis', in Loffelholz, M. and Weaver, D. (eds) Global Journalism Research: Theories, Methods, Findings, Future. Oxford: Blackwell Publishing, pp. 117-130.

Kunelius, R. and Renvall, M. (2010) 'Stories of a public: Journalism and the validity of citizens' testimonies', Journalism, 11(5), pp. 515-529.

Larsson, A. O. (2012) 'Understanding Nonuse of Interactivity in Online Newspapers: Insights From Structuration Theory', The Information Society, 28(4), pp. 253-263.

Lecheler, S. and Kruikemeier, S. (2016) 'Re-evaluating journalistic routines in a digital age: A review of research on the use of online sources', New Media \& Society, 18(1), pp. 156-171.

Lewis, J., Inthorn, S. and Wahl-Jorgensen, K. (2005) Citizens or consumers. Berkshire: Open University Press.

Lewis, J., Williams, A. and Franklin, B. (2008) 'A Compromised Fourth Estate? UK news journalism, public relations and news sources', Journalism Studies, 9(1), pp. 1-20.

Macnamara, J. (2016) 'The continuing convergence of journalism and PR: New insights for ethical practice from a three-country study of senior practitioners', Journalism \& Mass Communication Quarterly, 93(1), pp. 118-141.

Mancini, P. (1999) 'New Frontiers in Political Professionalism', Political Communication, 16(3), pp. 231-245.

Mare, A. (2014) 'New Media Technologies and Internal Newsroom Creativity in Mozambique', Digital Journalism, 2(1), pp. 12-28.

Mazzoleni, G. and Schulz, W. (1999) 'Democracy?, "Mediatization” of Politics: A Challenge for Democracy?', Political Communication, 16, pp. 247-261.

McNair, B. (2004) 'PR must die: Spin, anti-spin and political public relations in the UK, 1997 - 2004’, Journalism Studies, 5(3), pp. 37-41.

Meer, T. G. L. a. Van Der et al. (2017) 'Disrupting gatekeeping practices: Journalists' source selection in times of crisis', Journalism, 18(9), pp. 1107-1124.

Menke, M. et al. (2018) 'Convergence Culture in European Newsrooms', Journalism Studies, 19(6), pp. 881-904.

Myers, G. (2000) 'Entitlement and sincerity in broadcast interviews about Princess Diana', Media, Culture \& Society, 22, pp. 167-185.

O’Sullivan, J. and Heinonen, A. (2008) 'Old Values, New Media', Journalism Practice, 2(3), pp. 357-371.

Paulussen, S. (2012) 'Technology and the Transformation of News Work: Are Labor Conditions in (Online) Journalism Changing?', in Siapera, E. and Veglis, A. (eds) The 
Handbook of Global Online Journalism. Wiley-Blackwell, pp. 192-208.

Phillips, A. (2011) 'Faster and Shallower: Homogenisation, Cannibalization and the Death of Reporting', in Lee-Wright;, P., Phillips, A., and Witschge, T. (eds) Changing Journalism. New York: Routledge, pp. 81-98.

Philo, G. (1990) ‘Seeing IS Believing’, British Journalism Review, 1(4), pp. 58-64.

Pihl-Thingvad, S. (2015) 'Professional ideals and daily practice in journalism', Journalism, 16(3), pp. 392-411.

Rachul, C. and Caulfield, T. (2015) 'The media and access issues: content analysis of Canadian newspaper coverage of health policy decisions', Orphanet Journal of Rare Diseases, 10, p. 102.

Reich, Z. (2006) 'The Process Model of News Initiative: Sources lead first, reporters thereafter', Journalism Studies, 7(July), pp. 497-514.

Robinson, S. (2009) "“If you had been with us": mainstream press and citizen journalists jockey for authority over the collective memory of Hurricane Katrina', New Media \& Society, 11(5), pp. 795-814.

Ross, K. (2007) 'The journalist, the housewife, the citizen and the press: Women and men as sources in local news narratives', Journalism, 8(4), pp. 449-473.

Ryfe, D. M. (2006) 'Guest Editor's Introduction: New Institutionalism and the News', Political Communication, 23(2), pp. 135-144.

Schneider, B. (2013) 'Reporting Homelessness: Practice, product, profession', Journalism Practice, 7, pp. 47-61.

Shoemaker, P. J. and Reese, S. D. (2014) Mediating the Message in the 21st Century: A Media Sociology Perspective. New York: Routledge.

Smith, M. J. et al. (2008) 'Media Coverage of the Measles-Mumps-Rubella Vaccine and Autism Controversy and Its Relationship to MMR Immunization Rates in the United States', Pediatrics, 121(4), pp. 836-843.

Soloski, J. (1989) 'News reporting and professionalism: some constraints on the reporting of the news', Media, Culture \& Society, 11(2), pp. 207-228.

Splendore, S. (2017) 'The dominance of institutional sources and the establishment of non-elite ones: The case of Italian online local journalism', Journalism: Theory, Practice \& Criticism, p. 146488491772289.

Stones, R. (2005) Structuration Theory. Hampshire: Palgrave Macmillan.

Stroobant, J., De Dobbelaer, R. and Raeymaeckers, K. (2018) 'Tracing the Sources', Journalism Practice. Taylor \& Francis, 12(3), pp. 344-361.

Tuchman, G., Kaplan Daniel, A. and Benet, J. (eds) (1978) Hearth and home: images of women in the mass media. New York: Oxford University Press.

Usher, N. (2013) 'Marketplace public radio and news routines reconsidered: Between structures and agents', Journalism, 14(6), pp. 807-822. 
Zillman, D. (2008) 'Exemplification theory of media influence', in Jennings, B. and Dolf, Z. (eds) Media Effects: Advances in Theory and Research. Second. New Jersey: Laurence Erlbaum Associates. 